\title{
Democracia y libertad de expresión
} en América Latina: la amenaza del ímpetu devorador de los derechos*

\author{
Ximena Fuentes Torrijo
}

\begin{abstract}
En América Latina los derechos humanos se han invocado como el límite de lo permitido a las minorías en el poder: Pese a ello, el pensamiento regional parece coincidir con la idea liberal contramayoritaria de los derechos fundamentales, que promueve una particular visión de la democracia, en la que el ámbito del debate político estaría limitado por los derechos. Para muchos, esto revela claramente que el liberalismo clásico no se aproxima a la democracia como una noble actividad, sino como la opción de gobiemo menos mala. Para ilustrar este argumento, se cuestiona la visión liberal aplicada a la libertad de expresión, derecho especialmente relacionado con la democracia. Se sostiene que la visión liberal, según la cual la libertad de expresión se fundamenta en la protección de la autonomía personal, no repara en que el ejercicio del derecho puede obstaculizar la expresión de otros. Asi, la propia libertad de expresión puede interferir en el establecimiento de una democracia abierta y' plural. La opción ante la postura liberal plantea que, en buena medida, los contornos y el contenido de los derechos deben sujetarse al debate político, idea que parece chocar con lo dispuesto por el artículo 13 de la Convención Americana de Derechos Humanos, que adopta una posición extremadamente estricta frente a las restricciones de la libertad expresión. Esto demuestra que en la región se mira a la democracia con desconfianza y que está pendiente el desafio de un debate abierto y pluralista como la mejor fornu de proteger los derechos humanos.
\end{abstract}

\footnotetext{
" Parte de este artículo se basa en el trabajo "La libertad de expresión en Latinoamérica y la promoción de la democracia", a ser publicado próximamente en la revista de derecho de la Universidad Austral. Es parte de una investigación financiada por Fondecyt (proyecto 1010453) sobre "El derecho a la libertad de opinión e información frente al derecho al honor y a la vida privada en Chile".
} 


\section{Ximena Fuentes Torrijo}

\section{INTRODUCCIÓN}

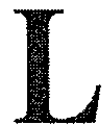

a historia de América Latina se ha caracterizado por la falta de democracia y las constantes violaciones de los derechos humanos. La relación entre ambas características es evidente en la medida en que la ausencia de democracia otorga un terreno propicio para que se cometan los más horribles atentados contra los derechos fundamentales de las personas. En este contexto latinoamericano, entonces, la invocación de los derechos humanos no ha tenido por objeto inmediato limitar decisiones aberrantes que haya tomado la mayoría en el poder, sino llamar la atención sobre los abusos de las minorías que con demasiada frecuencia se han hecho del poder en estos países ${ }^{1}$. Sin embargo, a pesar de que la historia en sí misma pareciera no justificar la necesidad de los argumentos contramayoritarios en nuestra región, gran parte de la idea latinoamericana de democracia parece coincidir con los postulados de un liberalismo clásico que ve en los derechos individuales fundamentales los límites al poder de la mayoría ${ }^{2}$. Esta visión de la democracia, que enfatiza el carácter limitador que tienen los derechos sobre la política, promueve una visión jurídica (y legalista) de las constitucio- nes, poniendo en segundo plano u olvidando las funciones políticas de una constitución o de los instrumentos internacionales que, al establecer catálogos de derechos fundamentales que los Estados se comprometen a respetar, también se podrían entender como integrando el orden constitucional. De lo anterior se sigue que hay diversas posiciones sobre cómo debe entenderse la democracia y, en particular, sobre la función que deben cumplir dentro de ella los derechos fundamentales. Al constitucionalismo jurídico se puede oponer un constitucionalismo político que, en vez de sacar los derechos del ámbito de la política, reconoce la existencia de un legítimo debate sobre el contenido y los contornos de los derechos fundamentales ${ }^{3}$.

\section{Hay diversas posiciones acerca de la función de los derechos fundamentales de la democracia.}

A diferencia de lo que está ocurriendo hoy en Europa, en que se discute sobre la compatibilización de los derechos humanos y el funcionamiento de la democracia, en los foros latinoamericanos ese debate ha estado y sigue estando, en general, ausente. Esto se puede apreciar

${ }^{1}$ A este respecto comparto gran parte de las ideas elaboradas por Fernando Atria en "Legalismo, Derechos y Política", artículo expuesto en SELA 2001, de próxima publicación en VV.AA., Derechos Fundamentales. (Buenos Aires, Editores del Puerto, 2002).

${ }^{2}$ Sobre la relación entre el liberalismo clásico y los derechos, ver: Loughlin, "Rights, Democracy, and Law", en Campell, et. al. Sceptical Essays on Human Rights, (Oxford, Oxford University Press, 2001), pág. 41 y ss.

${ }^{3}$ A este respecto ver: Bellamy. "Constitutive Citizenship versus Constitutional Rights: Republican Reflections on the EU Charter and the Human Rights Act", en ibid., pág. 15 y ss. 
claramente en la Carta Democrática aprobada por la Asamblea General de la OEA en septiembre de 2001, cuyo Artículo 3 dispone que: "Son elementos esenciales de la democracia representativa la celebración de elecciones libres y justas como expresión de la soberanía popular, el acceso al poder por medios constitucionales, el régimen plural de partidos y organizaciones políticas y el respeto a los derechos humanos y las libertades fundamentales".

\section{La Carta Democrática afirma que el debate democrático debe autolimitarse, comprometiéndose a respetar los derechos humanos.}

La Carta, entonces, en vez de afirmar que los derechos humanos se respetan a través del debate democrático, afirma que es el propio debate democrático el que, pudiendo violar los derechos, debe autolimitarse, comprometiéndose a respetarlos. Esta misma idea parece contenerse en el Artículo 8 que dispone: "El ejercicio de la democracia debe asegurar a todas las personas el goce de sus libertades fundamentales y los derechos humanos tal como aquellos consagrados en la Declaración Americana de los Derechos y Deberes del Hombre, la Convención Americana sobre Derechos Humanos y en el Protocolo de San Salvador sobre derechos económicos, sociales y culturales y los demás instrumentos interamericanos en materia de derechos humanos".

La existencia de determinados derechos humanos, contenidos en instrumentos internacionales como los que señala la Carta Democrática, tiende a darse por hecho. No es común encontrar entre los latinoamericanos autores que se pregunten sobre la conveniencia o no del establecimiento de determinados derechos, o sobre los adecuados límites de los mismos. En cambio, son muchos los que se apresuran a abrazar la idea de que los derechos humanos son autoevidentes, consustanciales a la persona humana y que están ahí para limitar a las mayorías. Así por ejemplo, entre nosotros, Carlos Peña ha señalado: "Un sistema político democrático no sólo debe ser entendido en un sentido puramente procedimental, es decir, por democracia no sólo hemos de entender un sistema político en el que las decisiones públicas se adoptan por personas o autoridades escogidas en conformidad a la regla de la mayoría. Más que eso -y así lo muestra la evolución de los sistemas políticos europeo-occidentales en la inmediata posguerra- una democracia supone la vigencia de ciertos principios de legitimidad que se erigen en fundamento, y a la vez en límite, del mero principio de las mayorías. El principal de esos principios de legitimidad, erigido en el constitucionalismo contemporáneo en un verdadero límite de la soberanía de los estados, es el principio de los derechos humanos"4.

\footnotetext{
${ }^{4}$ Peña, Carlos. Práctica Constitucional y Derechos Fundamentales, (Corporación Nacional de Reparación y Reconciliación, Colección Estudios N 5), pág. 190.
} 
En este contexto, escapa a la generalidad de la doctrina latinoamericana el problema real del apetito voraz de los derechos que puede amenazar con devorar los espacios de discusión pública, que tanto ha costado establecer y mantener en una región habituada a los regímenes autoritarios.

\section{El apetito voraz de los derechos puede amenazar con devorar los espacios de discusión pública.}

Pero no es mi intención aquí explorar con detención este amplio tema al que me he referido en los párrafos anteriores. Mi objetivo es más restringido. En las páginas que siguen trataré de ilustrar los problemas que puede suscitar la concepción simplemente contramayoritaria de los derechos en el ámbito de un derecho especialmente relacionado con el funcionamiento de la democracia, como lo es la libertad de expresión. Por oposición a esta concepción, que he llamado 'simplemente contramayoritaria', me referiré a una concepción distinta que ve en los derechos el resultado de una discusión política, abierta y transparente. De acuerdo con esta segunda visión, la gran mayoría de los derechos son mucho más dinámicos de lo que se tiende a pensar, y están sujetos a ciertos cambios en sus contenidos y contomos, como resultado de las discusiones políticas propias de la democracia ${ }^{5}$.

\section{LOS FUNDAMENTOS}

\section{DE LA LIBERTAD DE EXPRESIÓN}

La expresión, comparada con otras conductas humanas, goza de un lugar privilegiado, en tanto ha sido definida como un derecho fundamental de las personas que los sistemas políticos deben proteger y fomentar. En el ámbito del sistema interamericano de protección de los derechos humanos, se concibe la protección de la libertad de expresión (libertad de opinión y de información) como un derecho fundamental de la persona. Es así como el Artículo 4 de la Declaración Americana de los Derechos y Deberes del Hombre establece que: "Toda persona tiene derecho a la libertad de investigación, de opinión y de expresión y difusión del pensamiento por cualquier medio". Por su parte, el Artículo 13 de la Convención Americana de Derechos Humanos dispone que:

"Artículo 13. Libertad de pensamiento y de expresión

"1. Toda persona tiene derecho a la libertad de pensamiento y de expresión.

${ }^{5}$ Se podría objetar que hay ciertas instancias en que no podría tolerarse que los debates políticos de una democracia resultaran en una decisión genocida, por ejemplo. Al respecto, creo que es necesario, en el ámbito de los derechos humanos, distinguir entre derechos verdaderamente fundamentales, por una parte, y otros derechos humanos, por la otra. Sobre este punto ver: Atria. loc. cit. Es importante destacar que el hecho de que exista un área de derechos vedada al debate político, como podría ser la discusión de las circunstancias que justifiquen la comisión de actos genocidas, no es un buen argumento sobre la base del cual alegar que todos los derechos humanos deban ser retirados del debate político. 
Este derecho comprende la libertad de buscar, recibir y difundir informaciones e ideas de toda índole, sin consideración de fronteras, ya sea oralmente, por escrito o en forma impresa o artística, o por cualquier otro procedimiento de su elección.

"2. El ejercicio del derecho previsto en el inciso precedente no puede estar sujeto a previa censura sino a responsabilidades ulteriores, las que deben estar expresamente fijadas por la ley y ser necesarias para asegurar:

"a. el respeto a los derechos o a la reputación de los demás, o

"b. la protección de la seguridad nacional, el orden público o la salud o la moral públicas.

"3. No se puede restringir el derecho de expresión por vías o medios indirectos, tales como el abuso de controles oficiales o particulares de papel para periódicos, de frecuencias radioeléctricas, o de enseres y aparatos usados en la difusión de información o por cualesquiera otros medios encaminados a impedir la comunicación y la circulación de ideas y opiniones.

"4. Los espectáculos públicos pueden ser sometidos por la ley a censura previa con el exclusivo objeto de regular el acceso a ellos para la protección moral de la infancia y la adolescencia, sin perjuicio de 10 establecido en el inciso 2.
"5. Estará prohibida por la ley toda propaganda en favor de la guerra y toda apología del odio nacional, racial o religioso que constituyan incitaciones a la violencia o cualquiera otra acción ilegal similar contra cualquier persona o grupo de personas, por ningún motivo, inclusive los de raza, color, religión, idioma u origen nacional".

\section{Para la Convención Americana de Derechos Humanos, la libertad de expresión es un derecho humano anterior al Estado.}

La libertad de expresión en la Convención Americana de Derechos Humanos se ha concebido como un derecho humano que antecede al Estado. Es decir, se trataría de un atributo de las personas consustancial con su ser, que no es creado ni otorgado por el Estado ${ }^{6}$. Esta idea se encuentra en el propio preámbulo de la Convención, al señalar que se reconoce que "los derechos esenciales del hombre no nacen del hecho de ser nacional de determinado Estado, sino que tienen como fundamento los atributos de la persona humana"7. Al vincularse estrechamente con la noción de los atributos inherentes

\footnotetext{
${ }^{6}$ Gros Espiell, Héctor. La Convención Americana y la Convención Europea de Derechos Humanos. Análisis Comparativo, (Santiago, Editorial Jurídica de Chile,1991), pág. 24.

${ }^{7}$ Ver también el preámbulo de la Declaración Interamericana de Principios sobre la Libertad de Expresión, aprobada por la Comisión Interamericana de Derechos Humanos en su sesión ordinaria $N^{\circ}$ 108 (octubre, 2000), que señala que se considera que "el derecho a la libertad de expresión no es una concesión de los Estados sino un derecho fundamental". El Principio 1 dispone que: "La libertad de expresión, en todas sus formas y manifestaciones, es un derecho fundamental e inalienable, inherente a todas las personas. Es, además, un requisito indispensable para la existencia misma de una sociedad democrática".
} 
de la persona humana, el fundamento de la libertad de expresión parece encontrarse en un derecho individual al libre desarrollo de la personalidad y la autorrealización. Así concebida, la libertad de expresión se presenta, primero, como una libertad negativa en el sentido de excluir la invasión por parte del Estado de un área de autonomía de los individuos.

Esta manera de concebir los derechos humanos es propia del liberalismo clásico. Los derechos humanos consistirían en aquella área de autonomía individual vedada para el gobierno. Ya en la introducción de este trabajo se ha cuestionado esta particular visión de la democracia, en que la retórica de los derechos sirve para limitar, en forma creciente, el ámbito del debate político. Para algunos, esto es una clara manifestación de que el liberalismo clásico no se aproxima a la democracia como una noble actividad sino, simplemente, como la menos mala opción de gobierno $^{8}$. Esta idea liberal de los derechos humanos está sujeta a diversas objeciones y, en lo que se refiere a la expresión, el énfasis en la autonomía es aún más discutible. Si bien los derechos protegen una esfera de autonomía, ésta sólo se puede entender en la medida en que exista una real opción por diversos bienes colectivos. Como señala Koskennie$\mathrm{mi}$, en una sociedad que no ofrece opciones diferentes, la autonomía carece de sig- nificado 9 . Desde este punto de vista, la libertad de expresión no encuentra su fundamento último en la autonomía individual sino que depende de ciertos bienes colectivos que son evaluados independientemente del propio derecho a expresarse libremente ${ }^{10}$.

\section{El liberalismo clásico se aproxima a la democracia como la menos mala opción de gobierno.}

En efecto, se debe reconocer que la libertad de expresión no puede explicarse solamente en función de una directa relación con los atributos inherentes o consustanciales de la persona humana. Es decir, la libertad de expresión y su especial lugar como un derecho fundamental no pueden completamente explicarse por su relación con el desarrollo de la autonomía individual. En base a este tipo de fundamento es a veces difícil explicar por qué quienes reciben las expresiones de otros se encuentran obligados a tolerarlas. En relación con este punto es útil preguntarse, como lo hace Barendt, por qué la libertad de expresión sería particularmente importante para el desarrollo y el bienestar personal ${ }^{11}$. Como bien señala este autor, hay muchas otras actividades o necesidades humanas que también contribuyen al bienestar personal, pero que

\footnotetext{
${ }^{8}$ Loughlin. loc. cit, págs. 47-8.

${ }^{9}$ Koskenniemi. 'The effect of rights on political culture', en Alston (ed.), The EU and Human Rights, (Oxford, Oxford University Press, 1999), pág. 105.

${ }^{10}$ Ibid.

${ }^{11}$ Barendt. Freedom of Speech, (Oxford, Clarendon Press, 1985 [1996]), pág. 17.
} 
no gozan de la misma relevancia que la libertad de expresión en el discurso constitucional y, debemos agregar, tampoco en el discurso de los derechos humanos. Por ejemplo, Barendt hace notar la importancia de una adecuada vivienda y educación, de la utilidad de viajar gratis por el mundo para abrir los horizontes intelectuales de las personas, intereses éstos que no han obtenido la misma protección que la conseguida por la libertad de expresión. Por supuesto, en la medida en que la libertad de expresión puede concebirse como una libertad negativa, hay razones prácticas para distinguirla de esos otros derechos o eventuales derechos que también contribuirían al desarrollo de la personalidad y la autorrealización. Sin embargo, agrega Barendt, existen casos en que será difícil identificar un factor de autorrealización en algunas formas de expresión que se han intentado proteger constitucionalmente. Ése sería el caso de la libertad para publicitar determinados productos o de la libertad para hacer contribuciones financieras a campañas políticas o de ciertas formas de pomografía que, a primera vista, podrían vincularse con los argumentos sobre bienestar personal y autorrealización pero que, luego de un escrutinio más profundo, tienen -según Barendtpoca relación con la teoría según la cual el fundamento de la libertad de expresión se encuentra en el desarrollo moral e intelectual de cada persona; más bien, estos serían casos relacionados con una demanda general por mayor libertad, pero no explicarían la especial importancia de la libertad de expresión como derecho fundamenta $1^{12}$.

\section{Tras la protección de la libertad de expresión se promueve el desarrollo y fortalecimiento de la democracia.}

Tras la protección de la libertad de expresión existe un valor social o colectivo que se promueve: el desarrollo y fortalecimiento de la democracia. Esta vinculación con la democracia nos presenta el aspecto colectivo de la libertad de expresión, que se puede encontrar tanto en la libertad de emitir opiniones e informaciones, como en el derecho al acceso a la información. En el sistema interamericano de protección de los derechos humanos se recogen ambos aspectos de la libertad de expresión. Pero ¿es posible dar cabida a ambos aspectos en todos los casos? Lo que se sostiene en este artículo es que existe una tensión entre el aspecto individual (o libertario) de la libertad de expresión y el aspecto social que concibe esta libertad en función de su utilidad para promover la democracia. Esta tensión es real y no desaparece por la simple invocación de un supuesto principio de complementariedad. No siempre es posible proteger ambos aspectos de la libertad de expresión en forma simultánea, como propone la Corte Interamericana de Derechos en su decisión en el caso Ivcher Bronstein $^{13}$. El aspecto social puede implicar

\footnotetext{
${ }^{12}$ Ibid., págs. 14-19.

${ }^{13}$ Corte Interamericana de Derechos Humanos, caso Ivcher Bronstein, párrafo 149.
} 
restricciones al aspecto individual de la libertad de expresión, y esta hipótesis parece no haber sido contemplada en la Convención Americana de Derechos Humanos, que contiene un restringido número de posibles interferencias con este derecho.

\section{LAS IMPLICACIONES DEL ASPECTO} COLECTIVO DE LA LIBERTAD

\section{DE EXPRESIÓN}

Señalar que el fundamento de la libertad de expresión es doble, individual y colectivo, suele ser un lugar común. Así, en su opinión consultiva sobre la Colegiación Obligatoria de Periodistas, la Corte Interamericana de Derechos Humanos enfatiza que la libertad de expresión no sólo consiste en un derecho individual, que obliga a que nadie sea arbitrariamente menoscabado o impedido de manifestar su propio pensamiento, sino que también implica "un derecho colectivo a recibir cualquier información y a conocer la expresión del pensamiento ajeno"14. En su dimensión individual, el derecho se relaciona de un modo negativo con la democracia en el sentido de que impone una restricción a la voluntad de la mayoría. En su dimensión social, la relación con la democracia es positiva en el sentido de que la libertad de expresión se configura como un elemento necesario para el desarrollo y la promoción del proceso democrático mismo. Si bien es cierto que la libertad de expresión sirve muchas veces los intereses de la autonomía individual, lo relevante es poder identificar qué aspecto de la libertad de expresión otorga el mejor fundamento para la existencia de este derecho. $\mathrm{Al}$ respecto, comparto con Barendt la opinión según la cual el argumento que se basa en la democracia cumple el rol más relevante a la hora de determinar el ámbito de acción del derecho a la libertad de expresión ${ }^{15}$.

\section{Lo importante es poder identificar el aspecto de la libertad de expresión que mejor justifica la existencia del derecho.}

Esta idea es compartida por Fiss, quien, refiriéndose a la tradición estadounidense en materia de libertad de expresión, señala lo siguiente:

"Según la tradición alabada por Kalven, la libertad de expresión garantizada por la Primera Enmienda equivale a una protección de la autonomía -el derecho pone una coraza alrededor de quien habla. Sin embargo, la teoría que motiva esta protección, que inspiró a Kalven y,

${ }^{14}$ Corte Interamericana de Derechos Humanos, Opinión Consultiva OC-5/85, párrafo 30.

${ }^{15}$ Barendt, ob.cit., pág. 23 (mi traducción). El tercer fundamento al que se refiere es el que se basa en la democracia. Los otros dos fundamentos eran los basados en el descubrimiento de la verdad y en la autonomía o autorrealización personal. Ver también su capítulo $\mathrm{V}$, sobre la expresión política y el lugar preferente que ocupa en la jurisprudencia del tribunal europeo de derechos humanos y de algunos tribunales nacionales; pág. 145 y ss. 
antes de él, a Meiklejohn, y que ahora domina en este campo, formula el propósito subyacente de la Primera Enmienda en términos sociales o políticos: el propósito de la libertad de expresión no es la autorrealización individual, sino más bien la preservación de la democracia, y el derecho de un pueblo, en tanto pueblo, a decidir qué tipo de vida desea vivir. La autonomía no es protegida por su valor intrínseco, como podría insistir un kantiano, sino como un medio o instrumento para la autodeterminación colectiva. Le permitimos al pueblo hablar de manera que otros puedan votar. La expresión permite que la gente vote inteligente y libremente, consciente de todas las opciones y en posesión de toda la información relevante ${ }^{16}$.

Es a luz de esta tradición a la que refiere Fiss que uno debe leer los diversos fallos que la Corte Suprema de los Estados Unidos ha tenido ocasión de pronunciar en materia de libertad de expresión ${ }^{17}$.

La Corte Europea de Derechos Humanos hace tiempo reconoció la relación entre la libertad de expresión y el proce- so democrático en el caso Handyside $(1976)^{18}$. La misma idea es recogida en las sentencias pronunciadas en los casos Sunday Times $(1979)^{19}$ y Lingens $(1986)^{20}$, en los cuales la Corte Europea aprovechó de destacar la importancia de la prensa en la formación de la opinión pública en materias de interés público.

\section{Cuando la libertad de expresión se funda en la democracia, pierde fuerza como derecho fundamental y surgen razones para restringirlo.}

La Corte Interamericana de Derechos Humanos también ha reconocido esta íntima relación entre el funcionamiento de la democracia y la libertad de expresión ${ }^{21}$. Es así como ha señalado que:

"69. ...el mismo concepto de orden público reclama que, dentro de una sociedad democrática, se garanticen las mayores posibilidades de circulación de noticias, ideas y opiniones, así como el más amplio acceso a la información por parte de la sociedad en su conjunto. La libertad

\footnotetext{
${ }^{16}$ Fiss. Liberalism divided. Freedom of speech and the many uses of state power, (Colorado, Westview Press, Boulder, 1996), pág. 12 (mi traducción).

17 Ver por ejemplo Whitney vs. California, 274 U.S. 357, págs. 375-376, y Times v. Sullivan, 376 U.S. 254, pág. 270. En lo que se refiere a este último caso es recurrente en la literatura sobre libertad de expresión, ver citadas las siguientes palabras del juez Brennan: “...consideramos este caso a la luz de un profundo compromiso nacional con el principio de que el debate acerca de asuntos públicos debiera ser desinhibido, robusto y abierto, y que éste bien puede incluir ataques vehementes, cáusticos y a veces incómodos hacia el gobierno y los funcionarios públicos".

${ }^{18}$ Corte Europea de Derechos Humanos, caso Handyside, párrafo 50 (mi traducción).

${ }^{19}$ Ver párrafo 65.

${ }^{20}$ Ver párrafos 41 y 42 del fallo de la Corte Europea de Derechos Humanos en el caso Lingens.

${ }^{21}$ Más adelante, sin embargo, se verá que existen importantes diferencias entre el sistema interamericano y el europeo en lo que se refiere a las implicaciones que tiene la relación entre libertad de expresión y democracia.
} 
de expresión se inserta en el orden público primario y radical de la democracia, que no es concebible sin el debate libre y sin que la disidencia tenga pleno derecho de manifestarse...

"70. La libertad de expresión es una piedra angular en la existencia misma de una sociedad democrática. Es indispensable para la formación de la opinión pública. Es también conditio sine qua non para que los partidos políticos, los sindicatos, las sociedades científicas y culturales, y en general, quienes deseen influir sobre la colectividad puedan desarrollarse plenamente. Es, en fin, condición para que la comunidad, a la hora de ejercer sus opciones, esté suficientemente informada. Por ende, es posible afirmar que una sociedad que no está bien informada no es plenamente libre"22.

\section{El Convenio Europeo de Derechos Humanos condiciona las restricciones a la libertad de expresión a que sean necesarias en una sociedad democrática.}

El argumento según el cual la libertad de expresión encuentra su fundamento en las bondades de un debate abierto y plural que caracteriza a las sociedades democráticas es, como bien indica $\mathrm{Ba}$ rendt, un argumento que se opone a la consideración de este derecho como inherente a la persona humana ${ }^{23}$. Es que, si el fundamento de este derecho se encuentra en el funcionamiento de la democracia, necesariamente se deben abrir las posibilidades de discusión sobre eventuales circunstancias en que se justifique la imposición de restricciones a la libertad de expresión en función, precisamente, del fortalecimiento de la democracia. Es decir, cuando el fundamento de la libertad de expresión se encuentra en el desarrollo de un debate democrático, se diluye la idea de que este derecho sea intransable y con ella se desvanece la ilusión de estar frente a un derecho humano verdaderamente fundamental (entendiendo por tal un derecho cuyo contenido no estaría sujeto a los cambios políticos). $\mathrm{Si}$ aceptamos que los derechos, como señala Dworkin, juegan como 'cartas triunfo' que prevalecen sobre objetivos sociales que no logran alcanzar la condición de derechos ${ }^{24}$, en la medida en que se admitan restricciones fundadas en los diversos factores sociales envueltos, será difícil incluir a la libertad de expresión entre los 'derechos' 25 . Dicho de otra manera, al fundarse en la democracia, la libertad de expresión es despojada de parte importante de su fuerza como derecho funda-

\footnotetext{
${ }^{22}$ Opinión consultiva sobre Colegiación Obligatoria de Periodistas, OC-5/85, párrafo 70. Ver también sentencia de la Corte Interamericana en el caso "La Última Tentación de Cristo", párrafo 68, y la sentencia en el caso Ivcher Bronstein, párrafos 149 y 150.

${ }^{23}$ Barendt. $o b$. cit., pág 21.

${ }^{24}$ Dworkin. "Rights as Trumps", en Waldron, J (ed.). Theories of Rights, (Oxford, 1984 [1992]), pág. 153. Ver también: Taking Rights Seriously, (Massachusetts, Cambridge, 1977).

${ }^{25}$ Esta consecuencia también es identificada por Barendt, ob. cit., pág. 21.
} 
mental y es posible, entonces, justificar un amplio espectro de restricciones.

Es este tipo de razonamiento jurídi$\mathrm{co}$, en el que se reconoce el importante papel de la libertad de expresión en el establecimiento de una sociedad pluralista, aceptando la imposición de diversas restricciones, el que ha empleado la Corte Europea de Derechos Humanos en los varios casos sobre libertad de expresión sobre los que ha tenido ocasión de pronunciarse ${ }^{26}$. Respecto de este punto, es el propio Artículo 10 del Convenio Europeo de Derechos Humanos el que establece la relación fundamental que existe entre libertad de expresión y democracia ${ }^{27}$, condicionando todas las posibles restricciones a la libertad de expresión a que éstas sean necesarias en una sociedad democrática. Así, la libertad de expresión se ha visto restringida en un importante núme- ro de casos entre los que se destacan los casos Handyside ${ }^{28}$, Visions of Ectasy ${ }^{29} \mathrm{y}$ Otto-Preminger Institute v. Austria ${ }^{30}$.

\section{En el contexto interamericano, el aspecto individual y el aspecto social de la libertad de expresión son de igual valor y deben garantizarse en forma simultánea.}

El empleo del criterio de necesidad dentro de una sociedad democrática para definir la compatibilidad o incompatibilidad de una determinada restricción a la libertad de expresión se ha traducido en Europa en una distinción entre expresiones políticas, por una parte, y otro tipo de expresiones, tales como las expresiones comerciales y artísticas, por la otra. Las

${ }^{26}$ En su sentencia en el caso The Observer and Guardian vs. Reino Unido (1991), la Corte Europea advirtió eso sí que las excepciones a la libertad de expresión deben ser interpretadas en forma restringida y que deben estar convincentemente justificadas (ver párrafo 59 de la sentencia).

${ }^{27}$ El artículo 10 del Convenio Europeo de Derechos Humanos dispone:

"1.- Toda persona tiene derecho a la libertad de expresión. Este derecho comprende la libertad de opinión y la libertad de recibir o de comunicar informaciones o ideas sin que pueda haber injerencia de autoridades públicas y sin consideración de fronteras. El presente artículo no impide que los Estados sometan a las empresas de radiodifusión de cinematografía o de televisión a un régímen de autorización previa.

"2.- El ejercicio de estas libertades, que entrañan deberes y responsabilidades, podrá ser sometido a ciertas formalidades, condiciones, restricciones o sanciones, previstas por la ley, que constituyan medidas necesarias, en una sociedad democrática para la seguridad nacional, la integridad territorial o la seguridad pública, la defensa del orden y la prevención del delito, la protección de la salud o de la moral, la protección de la reputación o de los derechos ajenos, para impedir la divulgación de informaciones confidenciales o para garantizar la autoridad y la imparcialidad del poder judicial".

${ }^{28}$ Corte Europea de Derechos Humanos, sentencia en el caso Handyside, párrafos 52 y 57.

${ }^{29}$ Corte Europea de Derechos Humanos, sentencia en el caso Wingrove vs. Reino Unido (1996), párrafo 57.

${ }^{30}$ Corte Europea de Derechos Humanos, sentencia en el caso Otto-Preminger Institute vs. Austria (1994), párrafo 50 y ss.

${ }^{31}$ Corte Europea de Derechos Humanos, caso Mïller y otros (1988), párrafo 27. 
expresiones políticas son las que obtienen el mayor grado de protección. Las expresiones artísticas y comerciales, a pesar de reconocerse su carácter de expresión para los efectos del Artículo 10, suelen recibir una menor protección, precisamente porque, en principio, tratándose de ellas, existiría un mayor espacio para aceptar interferencias, pudiéndose ponderar ciertos intereses sociales sin por ello transformar las restricciones en incompatibles con la existencia de una sociedad democrática. Así, por ejemplo, en el caso Müller y otros (1988), enfrentada a la orden de retirar una serie de pinturas obscenas de una exhibición artística gratuita y destinada para un gran público, incluidas familias con sus niños, la Corte Europea estimó que, si bien el Artículo 10 del Convenio no cubre exclusivamente las expresiones explícitamente políticas sino también las expresiones artísticas ${ }^{31}$,el interés legítimo del Estado de proteger la moral, en un contexto europeo en que no existe un concepto uniforme de moralidad, justificaba la restricción impuesta ${ }^{32}$.

En lo que se refiere a las expresiones comerciales, es necesario considerar el caso Markt Intern (1989), relativo a una publicación comercial en que se acusaba a una determinada empresa de venta de productos cosméticos por catálogo de no haber dado cumplimiento a las condiciones sobre devolución de productos ofrecidas por la empresa. En este caso, la Cor- te Europea afirmó que las expresiones comerciales también estaban cubiertas por el Artículo 10 del Convenio Europeo sobre Derechos Humanos, pero que en las circunstancias del caso, el resguardo de la competencia leal justificaba la imposición de una restricción a una publicación referida a un incidente comercial aislado que podría haber ocasionado daños gratuitos a la reputación comercial de una determinada compañía ${ }^{33}$.

\section{Una prohibición amplia de las restricciones a la libertad de expresión se traduce en una visión negativa del control gubernamental sobre ella.}

Los casos anteriormente referidos y el énfasis que la Corte Europea de Derechos Humanos ha puesto sobre el fundamento democrático de la libertad de expresión, ponen de manifiesto una diferencia fundamental entre el sistema europeo y el sistema americano de protección supranacional de la libertad de expresión. La Convención Americana de Derechos Humanos no se refiere explícitamente a la relación que existe entre libertad de expresión y promoción de la democracia $^{34}$. Ciertamente, no puede omitirse el hecho de que la jurisprudencia de los órganos interamericanos de supervisión ha

${ }^{32}$ Ibid, párrafos 35 y 36.

${ }^{33}$ Corte Europea de Derechos Humanos, caso Markt Intern (1989), párrafos 35 y 36.

${ }^{34}$ Debe advertirse en todo caso que el Artículo 29 de la Convención Americana dispone que la interpretación de la Convención no puede excluir otros derechos y garantías que se derivan de la forma 
reconocido la importancia de la libertad de expresión para el desarrollo de una sociedad democrática ${ }^{35}$. Sin embargo, al señalar que el aspecto individual y el aspecto social tienen la misma importancia, como lo ha hecho la Corte Interamericana, y que, por lo tanto, ambos deben ser garantizados en forma simultánea, en los hechos se está dando preponderancia al aspecto individual, puesto que a este aspecto individual se otorga la calidad de intocable, mientras que siempre se podría presentar algún argumento plausible según el cual el aspecto social resulta, a la larga, mejor protegido en un entorno de completa libertad.
SOMBRAS DE SOSPECHA SOBRE

LA REGULACIÓN DE LA LIBERTAD DE EXPRESIÓN

Una de las diferencias más destacables entre el Convenio Europeo y la Convención Americana es que ésta última prohíbe expresamente toda forma de censura $^{36}$. Se ha podido apreciar que, en varios casos, la Corte Europea ha estimado legítimas ciertas formas de censura ${ }^{37}$. Las diferencias entre ambas convenciones han sido reconocidas por la Corte Interamericana de Derechos Humanos en su opinión consultiva sobre Colegiación

democrática representativa de gobiemo. Sin embargo, nótese que se habla sólo de derechos y garantías, excluyéndose otros intereses que no reúnan esas características. En este contexto, es interesante subrayar lo que señala la Declaración Americana de Derechos y Deberes del Hombre, cuyo Artículo XXVIII dispone que: "Los derechos de cada hombre están limitados por los derechos de los demás, por la seguridad de todos y por las justas exigencias del bienestar general y el desenvolvimiento democrático".

${ }^{35}$ Así, en su opinión consultiva OC-5/85, la Corte Interamericana señaló, en el párrafo 70, que: "La libertad de expresión es una piedra angular en la existencia misma de una sociedad democrática. Es indispensable para la formación de la opinión pública. Es también conditio sine qua non para que los partidos políticos, los sindicatos, las sociedades científicas y culturales, y en general, quienes deseen influir sobre la colectividad puedan desarrollarse plenamente. Es, en fin, condición para que la comunidad, a la hora de ejercer sus opciones, esté suficientemente informada. Por ende, es posible afirmar que una sociedad que no está bien informada no es plenamente libre". En el caso Ivcher Bronstein, párrafo 149, la Corte se pronunció en el siguiente sentido: "La Corte considera que ambas dimensiones [la individual y la social] poseen igual importancia y deben ser garantizadas en forma simultánea para dar efectividad total al derecho a la libertad de expresión en los términos previstos por el Artículo 13 de la Convención. La importancia de este derecho destaca aún más al analizar el papel que juegan los medios de comunicación en una sociedad democrática, cuando son verdaderos instrumentos de la libertad de expresión y no vehículos para restringirla, razón por la cual es indispensable que recojan las más diversas informaciones y opiniones". Y, por último, en el caso de la película "La Última Tentación de Cristo", la Corte, en los párrafos 66 y 67 reitera lo señalado en las decisiones anteriores.

${ }^{36}$ En la Convención Americana sólo cabrían dos casos de censura: la censura previa con el exclusivo objeto de regular el acceso a los espectáculos públicos para la protección de la moral de la infancia y la adolescencia, y "la prohibición de toda propaganda en favor de la guerra y toda apología del odio nacional, racial o religioso que constituyan incitaciones a la violencia o cualquiera otra acción ilegal similar contra cualquier persona o grupo de personas, por ningún motivo, inclusive los de raza, color, religión, idioma u origen nacional".

${ }^{37}$ Ver casos Handyside, Mïller y Otros, Wingrove vs. Reino Unido, y Otto Preminger Institute vs. Austria. 
Obligatoria de Periodistas (OC-5/85), calificándolas como 'diferencias significativas' ${ }^{38}$. La propia Corte destaca en esta opinión consultiva el hecho de que la prohibición a las restricciones a la libertad de expresión sea más explícita que en el Convenio Europeo, 1legando a concluir que:

"50. ...La comparación hecha entre el Artículo 13 y las disposiciones relevantes de la Convención Europea (Artículo 10) demuestra claramente que las garantías de la libertad de expresión contenidas en la Convención Americana fueron diseñadas para ser las más generosas y para reducir al mínimum las restricciones a la libre circulación de las ideas".

Esta prohibición 'generosa' a las restricciones a la libertad de expresión, en el contexto interamericano de protección de los derechos humanos, se traduce en una visión negativa hacia el control gubernamental que pueda ejercerse sobre la libertad de expresión. Es así, como en esta misma opinión consultiva la Corte agrega que:

"55. ...resulta contradictorio con la Convención todo acto del poder público que implique una restricción al derecho de buscar, recibir y difundir informaciones e ideas, en mayor medida o por medios distintos de los autorizados por la misma Convención; y todo ello con independencia de si esas restricciones aprovechan o no al gobierno".

\section{El dinero y el poder pueden dañar} seriamente la libertad de expresión.
Pero sabemos que los gobiernos no son los únicos enemigos de la libertad de expresión. El dinero y el poder también pueden amenazar y dañar seriamente la libertad de expresión. La Corte Interamericana, en todo caso, se ha referido al peligro que representan los monopolios u oligopolios en la propiedad de los medios de comunicación y está consciente de la necesidad de evitarlos. Lo que llama la atención, sin embargo, es que la Corte no haya indagado sobre las diversas formas que existen para combatir estos monopolios económicos o los efectos de los mismos sobre la libertad de expresión. Pareciera que la Corte sólo piensa en una regulación económica de estos monopolios, pero ¿qué pasa con aquellas regulaciones estatales que estuvieran dirigidas a hacer el debate más abierto y plural? ¿Hasta qué punto ese tipo de regulación no económica sería compatible con las disposiciones de la Convención Americana de Derechos Humanos? Tampoco repara la Corte en la posible existencia de monopolios ideológicos, es decir, aquellos en que, no existiendo concentración de la propiedad de los medios de comunicación, los diversos propietarios de ellos comparten una misma ideología y la imponen a través de sus medios.

Éste es un punto importante. EI énfasis en el aspecto individual de la libertad de expresión se traduce en el rechazo a todo tipo de regulación. Cualquier regulación estatal aparece como sospechosa. Esta manera de concebir la libertad de

${ }^{38}$ Ver párrafos 45 a 49. 
expresión ha encontrado eco en el Tribunal Constitucional chileno, el cual en una sentencia pronunciada respecto del reclamo de inconstitucionalidad de determinadas disposiciones del proyecto de ley sobre "Libertad de Expresión, Información y Ejercicio del Periodismo", estableció como contrario a los preceptos de la Constitución chilena permitir que el Estado obligara a una persona o a algún medio a entregar determinadas informaciones ${ }^{39}$. En este entendido, el Tribunal Constitucional consideró que no correspondía que la ley en cuestión obligara al Estado a garantizar el pluralismo político en el sistema informativo, desautorizándolo para asegurar la expresión efectiva de las distintas corrientes de opinión. En opinión del Tribunal:

"31) ...desde el momento en que se impone al Estado la obligación de equilibrar el flujo noticioso a fin de pretender una pluralidad ideológica o cultural, y para así hacerlo ha de imponer obligaciones a los medios de comunicación social, significa una intromisión indebida en las decisiones que pueda adoptar un medio de comunicación, interferencia que no sólo constituye una clara violación a la autonomía de ese medio -que la Constitución reconoce, ampara y garantizasino, además, una violación directa a la libertad de emitir opinión y de informar sin censura previa, en cualquier forma y por cualquier medio...Tan sensible es esta libertad, que su reconocimiento desde antiguo en nuestro régimen republicano se ha expresado con fórmula lapidaria: 'sin censura previa', término cuyo quid conceptual hoy no es otro que 'sin interferencias' de nadie".

\section{El énfasis en el aspecto individual de la libertad de expresión se traduce en el rechazo de todo tipo de regulación.}

La sentencia comentada se opone a todo tipo de regulación que pudiera interpretarse como una interferencia con la autonomía de los medios de comunicación para decidir qué opiniones o informaciones divulgar. Se trata de un argumento eminentemente liberal en su sentido clásico; es decir, que ve en el Estado al enemigo natural de la libertad ${ }^{40}$. El énfasis descansa en la libertad o autonomía de quien se expresa o del medio de comunicación a través del cual se expresa, y se puede apreciar que la contribución que la libertad de expresión efectúa hacia el desarrollo democrático no estuvo presente en la mente de los jueces del tribunal constitucional chileno. Esto es grave, si se piensa que Chile es un país en el que la concentración económica e ideológica de los medios es especialmente marcada ${ }^{4}$.

${ }^{39}$ Tribunal Constitucional de la República de Chile, Sentencia Rol 226 (1995), párrafos 21 a 24.

${ }^{40}$ Fiss. La Ironia de la Libertad de Expresión, (Barcelona, Gedisa, 1996, edición en castellano 1999), pág. 72.

${ }^{41}$ Para un estudio detallado sobre esta materia, ver Sunkel y Geoffroy. Concentración Económica de los Medios de Comunicación, (Santiago de Chile, Lom Ediciones, 2001). 
El papel activo del Estado en la promoción de una prensa democrática no se opone necesariamente al principio de la libertad de expresión.

La experiencia comparada nos demuestra que un papel activo del Estado en la promoción de una prensa democrática no es necesariamente contrario al principio de la libertad de expresión. En Estados Unidos la Corte Suprema se pronunció a favor de una ley que obligaba a las radioemisoras a transmitir informaciones de interés público y a mostrar las distintas posiciones involucradas en el debate, en el caso Red Lion Broadcasting Co. vs. FCC $(1969)^{42}$. La teoría detrás de esta legislación se conoce como la 'fairness doctrine', que fue explicada en los siguientes términos por la Corte Suprema en Red Lion:

"Del mismo modo que el gobierno puede limitar el uso de un equipo amplificador de sonido que potencialmente es tan ruidoso como para ahogar la expresión privada civilizada, también puede limitar el uso del equipo comunicacional. La libertad de expresión del comunicador, el usuario de una banda de sonido, o cualquier otro individuo no poseen un derecho a sofocar la expresión de otros".
Este fallo se refería específicamente a las limitaciones tecnológicas del uso del espectro radiofónico. Sin embargo, la tecnología no es el único factor que puede limitar el acceso a los medios de comunicación ni explicar el potencial de los mismos para frustrar el pluralismo deseado por el ideal democrático. Fiss señala que la teoría más plausible de la 'fairness doctrine' considera que es la economía y no la tecnología la fuerza que constriñe a la prensa ${ }^{43}$.Para Fiss, el hecho de que la oferta informativa que brindan los medios de comunicación esté gobernada por las leyes del mercado crea el riesgo de que la cobertura informativa sea sesgada. No se trata de que se puedan o no establecer monopolios económicos en relación con los medios de comunicación, sino que las leyes del mercado tienden a que las empresas de los medios de comunicación prefieran maximizar sus ingresos en desmedro de la utilidad social que se cumple al dar cobertura a ideas que no sirven para obtener auspiciadores o vender productos $^{44}$. A esto se debe agregar que en algunos países como Chile no existe pluralismo ideológico en el empresariado, lo cual se traduce en una fácil manipulación de los medios de comunicación cuyos ingresos dependen en gran medida de la venta de publicidad ${ }^{45}$.

42395 U.S. 367 . Debe advertirse que durante la administración del presidente Reagan, la doctrina formulada en este caso fue eliminada como inconstitucional. Ver, Fiss. La ironía de la libertad de expresiôn, pág. 81.

${ }^{43}$ Ibid., pág. 81.

${ }^{44} \mathrm{Ibid}$., pág.75.

${ }^{45}$ Sobre las presiones económicas que ejercen los avisadores sobre los medios ver: Otano y Sunkel, "Libertad de los Periodistas en los Medios", en González y Viveros, ob.cit., págs. 278-281. En el recien- 
A pesar de la existencia de un claro problema en el papel que cumplen los medios y la prensa en la promoción de una sociedad pluralista, América Latina parece insistir en el aspecto individual de la libertad de expresión, relegando a segundo plano el tema de la regulación de los medios para favorecer el debate público abierto. Si se leen los informes de la Relatoría Especial para la Libertad de Expresión de la Comisión Interamericana de Derechos Humanos, llama la atención que no se trate en ninguno de ellos el problema de la concentración de los medios y la manipulación ideológica de los mismos por parte de propietarios y avisadores. Es cierto que en Latinoamérica existen situaciones brutales de represión a la libertad de expresión que justificadamente pueden parecer más apremiantes que la presión que ejerce el poder del dinero. Los siguientes son los problemas más graves identificados por la Relatoría Especial para la Libertad de Expresión: los asesinatos de periodistas, las múltiples amenazas de que son objeto los periodistas, la existencia de leyes de desacato, el uso de figuras penales como las injurias y las calumnias para acallar la crítica a los gobiemos y sus funcionarios, y la aplicación de diversas formas de censura previa ${ }^{46}$. Estas situaciones se concentran en las acciones contrarias a la libertad de expresión que se cometen por parte de los gobiernos. Pero también existen acciones contrarias a la libertad de expresión que surgen de la propia sociedad civil y que no han sido hasta ahora materia que merezca la atención de la Relatoría.

\section{Hay acciones contrarias a la libertad de expresión que surgen de la propia sociedad civil.}

Llama la atención por ejemplo que, al referirse al tema de la relación entre la discriminación de la mujer y la libertad de expresión, el relator especial se concentre exclusivamente en la necesidad de promover una mayor libertad de expresión que, a su juicio, contribuiría a una mayor participación activa de la mujer en la denuncia de abusos y en la búsqueda de soluciones que resultarían en un mayor respecto a todos sus derechos fundamentales ${ }^{47}$. Se omite, entonces, toda mención a la posibilidad de que la propia libertad de expresión sea la que contribuya a la menor participación política de la

te estudio de Sunkel y Geoffroy sobre Concentración Económica de los Medios de Comunicación, se concluye que la raíz de la falta de pluralismo en los medios de comunicación se debe, en gran medida, a la existencia de un empresariado ideologizado: "Nuestra hipótesis sería que la raíz del problema se encuentra en el empresariado chileno: esto es, un empresariado ideológicamente homogéneo, educado en una matriz económica neoliberal y en un conservadurismo valórico donde quienes se salen de este esquema constituyen excepciones a la tendencia general. Esto incluye no sólo a los propietarios de los medios sino también al conjunto de los avisadores": ob. cit., pág. 115.

${ }^{46}$ Ver informes de la Relatoría para la Libertad de Expresión: 1998, 1999 y 2000.

47 "Informe de la Relatoría para la Libertad de Expresión", en Informe Anual de la Comisión Interamericana de Derechos Humanos 1999, (OEA/Ser. L/V/II.106, Doc. 3 rev.), pág. 32. 
mujer y la violencia contra su persona. Éste es un tema que ha sido explorado por algunas feministas, especialmente en los Estados Unidos, para quienes la pornografía, por ejemplo, puede servir para perpetuar la subordinación de la mujer ${ }^{48}$. Fiss, al examinar la constitucionalidad de una legislación de Indianápolis cuyo objeto era prohibir la comercialización (o tráfico) de cierto tipo de pornografía, aclara cómo una restricción a la libertad puede tener por efecto, precisamente, establecer las condiciones para un debate más abierto, en la medida que la prohibición aspiraba a efectuar una pequeña contribución para erradicar la dinámica social que resulta de la subordinación de la mujer ${ }^{49}$.

Llama la atención también, como ya se dijo anteriormente, que la Corte Interamericana, en su opinión consultiva OC-5/85, se haya referido sólo a una forma de restricción derivada de la acción no estatal: la existencia de monopolios u oligopolios en la propiedad de los medios de comunicación ${ }^{50}$. Ninguna mención se hace a las restricciones que el propio mercado impone sobre el contenido de las informaciones ni a cómo los privados, sin la necesaria existencia de monopolios sobre la propiedad de los medios, pueden limitar el ámbito del debate público. Esta seria omisión explica que la Corte Interamericana deseche de plano toda posible regulación del mercado de la información que no tenga por exclusivo objeto la eliminación de los monopolios en la propiedad y control de los medios de información $^{51}$. Esta posición se ha plasmado en la Declaración de Principios sobre Libertad de Expresión aprobada por la Comisión Interamericana de Derechos Humanos en octubre de $2000^{52}$.

Es posible que la libertad de expresión contribuya a la menor participación política de la mujer.

¿Cómo explicar esta posición que se ha adoptado en el sistema interamericano de protección de la libertad de expresión? La explicación más plausible parece encontrarse en el escepticismo reinante en Latinoamérica respecto del funcionamiento de la democracia. Como se ha dicho, la historia de América Latina parece caracterizarse precisamente por la ausencia de democracia. Los regímenes autoritarios que han regido por décadas los destinos de esta parte del globo se han encargado de cometer las más graves violaciones a los derechos humanos. En este con-

48 Ver Mackinnon. Only words, (Harvard University Press, 1993), in pássim.

${ }^{49}$ Fiss, Liberalism Divided, pág. 87 (mi traducción).

${ }^{50}$ Corte Interamericana de Derechos Humanos, Opinión Consultiva OC-5/85, párrafo 56.

${ }^{51} \mathrm{Ibid}$, párrafo 54.

52 Ver especialmente el Principio 5: "La censura previa, interferencia o presiôn directa o indirecta sobre cualquier expresión, opinión o información difundida a través de cualquier medio de comunicación oral, escrito, artístico, visual o electrónico, debe estar prohibida por la ley. Las restricciones en la circulación libre de ideas y opiniones, como así también la imposición arbitraria de información y la creación de obstáculos al libre flujo informativo, violan el derecho a la libertad de expresión". 
texto, al efectuar una comparación entre el sistema europeo y el sistema interamericano de protección de los derechos humanos, no puede dejar de constatarse que el segundo ha debido enfrentarse con violaciones atroces, que el sistema europeo que nace en los años cincuenta no ha tenido, felizmente, ocasión de conocer ${ }^{53}$.

\section{A diferencia del sistema}

\section{europeo, el sistema interamericano} de protección de los derechos humanos ha debido enfrentar violaciones atroces.

En vista de la falta de democracia en Latinoamérica, el sistema interamericano ha preferido reglar en forma más detallada que el sistema europeo, los derechos protegidos y las situaciones de excepción contempladas. Esto es claro, como se ha visto en las páginas precedentes, en materia de libertad de expresión. Flexibilizar las disposiciones de la Convención Americana, se piensa, es demasiado riesgoso, ya que los gobiernos autoritarios aprovecharían cualquier posible justificación para limitar los derechos garantizados en la Convención. En Europa, por el contrario, se reconoce a los gobiernos un cierto margen de apreciación en la implementación y cumplimiento de los derechos garantizados. A diferencia del sistema europeo, la jurisprudencia de los órganos de supervisión del sistema interamericano de derechos humanos no contempla la doctrina del margen de apreciación y muchos, entre ellos el propio presidente de la Corte Interamericana -Antonio Cançado Trindade-, consideran que éste es un aspecto positivo. De hecho, Cançado Trindade califica como un hecho afortunado el que la doctrina del margen de apreciación no haya encontrado un desarrollo explícito en la jurisprudencia de la Convención Americana de Derechos $\mathrm{Hu}$ manos $^{54}$. Esta posición, a mi juicio, es equivocada y omite un análisis más profundo acerca de los fundamentos de la doctrina del margen de apreciación. Se podría incluso decir que esta posición es consecuencia de una visión escéptica de la política y, en particular, de la propia democracia, la cual no estaría, al parecer, preparada para debatir sobre los derechos de las personas. Así, la falta de tradición democrática en la región ha tenido un efecto perverso: se nos ha llevado a pensar que la mejor forma de proteger los derechos humanos es retirándolos de la política, aunque ésta se desarrolle en forma abierta, plural y transparente.

La negación demasiado rápida de la utilidad de la doctrina del margen de apreciación en esta parte del hemisferio significa negar también la posibilidad de establecer un esquema democrático distinto del propugnado por la teoría liberal. En lo que se refiere a la libertad de expresión, la negación de la teoría del margen

${ }^{53}$ Cançado Trindade. El Derecho Internacional de los Derechos Humanos en el Siglo XXI, (Santiago, Editorial Jurídica de Chile, 2001), pág. 387.

${ }^{54}$ Ibídem. 
de apreciación significa desechar de plano que en algunos países el debate democrático plural y transparente introduzca la necesidad de limitar la libertad de expresión de algunos para garantizar la libertad de expresión de otros, que de otra manera permanecerían marginados de la arena pública.

\section{DESMITIFICANDO LA DOCTRINA DEL MARGEN DE APRECIACIÓN EN LATINOAMÉRICA}

Una forma simple de explicar la doctrina del margen de apreciación en el sistema europeo de protección de los derechos humanos señala que la diversidad cultural existente en Europa justifica que se autorice cierta discreción a los Estados para definir el ámbito de los derechos protegidos por el sistema. Esta diversidad cultural no sería tan evidente en el caso latinoamericano en que, se dice, es posible encontrar mayor consenso en los derechos fundamentales, motivo por el cual no ha surgido ni se requiere una doctrina del margen de apreciación como la que se observa en el sistema europeo. Pero, aparte del consenso que pueda existir respecto de los derechos realmente fundamentales, respecto de la gran mayoría de los derechos humanos también existe en Latinoamérica un legítimo desacuerdo acerca de su contenido. En este sentido las sociedades la- tinoamericanas no son distintas de otras sociedades, en particular de las europeas, existiendo también una amplia diversidad cultural. La doctrina del margen de apreciación, entonces, podría servir en esta región para dar cabida a esta diversidad.

\section{La diversidad cultural existente} en Europa justificaría cierta discrecionalidad de los Estados para definir el ámbito de los derechos protegidos.

Sin embargo, el fundamento de la doctrina del margen de apreciación no se agota en la preservación del carácter multicultural de las sociedades, sino que su fundamento último se encuentra en la búsqueda de un equilibrio entre las facultades de supervisión que se entregan a ciertos órganos supranacionales y el poder soberano de los pueblos para determinar sus propias leyes ${ }^{55}$. En este sentido, la doctrina del margen de apreciación guarda estrecha relación con los debates que se han dado a nivel nacional sobre el ámbito adecuado de la revisión judicial o constitucional de la legislación. De esta manera, no se trata simplemente de una deferencia hacia la identidad cultural de cada país, sino que a través de la doctrina del margen de apreciación se ha tratado de preservar el valor de la democracia. Como señala Mahoney:

${ }^{55}$ Mahoney. "Marvellous Richness of Diversity or Invidious Cultural Relativism", en Human Rights Law Journal, (1998, vol. 19, № 1), pág. 3. 
"El Convenio Europeo de Derechos Humanos está basado en una determinada filosofía política, según la cual la democracia política es el mejor sistema de gobierno para asegurar el respeto de las libertades fundamentales y de los derechos humanos. Cualquier teoría sobre la interpretación o la revisión que pueda hacer la Corte debe ser compatible con este supuesto básico de la teoría política. En una sociedad democrática pluralista en varios de los temas cubiertos por el Convenio existirá un espectro de opiniones diferentes pero aceptables. La decisión de la Corte respecto de algún punto del Convenio se referirá frecuentemente a determinar si la opción de las autoridades nacionales se ha mantenido dentro del espectro permisible"s6.

Existen varios detractores de la doctrina del margen de apreciación; sin embargo, sus críticas no logran destruir su utilidad para realizar esta necesaria compatibilización entre democracia y derechos humanos. Éste es el punto del cual Cançado Trindade no se hace cargo. Para él la doctrina del margen de apreciación sólo se justifica en el contexto de la existencia de un Estado de Derecho. Como el Estado de Derecho no existiría todavía en América Latina, concluye que no necesitamos ninguna doctrina de margen de apreciación, lo cual se vería reforzado por el hecho de que la mayoría de las violaciones de los derechos humanos en esta región se refiere a la violación de derechos inderogables ${ }^{57}$. Se olvida, entonces, de la importancia que tiene en un Estado de Derecho el respeto por las decisiones del pueblo y la inconveniencia de traspasar a órganos de supervisión supranacionales no elegidos la responsabilidad de decidir sobre las políticas que deben implementarse dentro de un país.

\section{El fundamento de la doctrina del margen de apreciación es la búsqueda de equilibrio entre las facultades de supervisión y el poder soberano de los pueblos para determinar sus leyes.}

En materia de libertad de expresión, la doctrina del margen de apreciación ha obtenido gran aplicación en el contexto europeo. De hecho, la doctrina fue por primera vez elaborada explícitamente por la Corte en un caso de libertad de expresión, el caso Handyside, en el que se justificó el reconocimiento de un amplio margen de apreciación de las autoridades nacionales, en función de la imposibilidad de identificar una concepción común sobre ciertos valores morales ${ }^{58}$. En otro caso sobre libertad de expresión, el caso Sunday Times, la Corte especificó que la amplitud del margen de apreciación de-

\footnotetext{
${ }^{56}$ Mahoney. "Judicial Activism and Judicial Self-Restraint in the European Court of Human Rights: Two Sides of the Same Coin", en Human Rights Law Joumal (1990, vol. 11), pág. 81.

${ }^{57}$ Cançado Trindade. ob. cit., pág. 386-7.

${ }^{58}$ Corte Europea de Derechos Humanos, caso Handyside, párrafos 48 y 49.
} 
pende del fin que se persiga con la restricción impuesta ${ }^{59}$. En ese caso, se estimó que la protección de la autoridad e imparcialidad del poder judicial era una noción más o menos objetiva que justificaba un menor margen de apreciación para las autoridades nacionales. De esta manera, un examen de los diversos casos en que la Corte Europea ha debido pronunciarse sobre la doctrina del margen de apreciación en materia de libertad de expresión permite apreciar que se han seguido los siguientes criterios en su aplicación $^{60}$ :

(i) El tipo de restricción que se impone sobre la libertad de expresión. Así, respecto de las restricciones más severas, la Corte tiende a ser más estricta en cuanto al reconocimiento de un margen de apreciación para las autoridades nacionales.

(ii) El tipo de expresión. Así, tratándose de expresiones relativas a cuestiones políticas, la Corte tiende a reconocer muy poco margen de apreciación. Distinto es el caso de las expresiones comerciales o blasfemas.

(iii) La clase de interés que se pretende proteger. Es así como la protección de la moral admite un mayor campo para la aplicación de la doctrina del margen de apreciación, en cambio, la seguridad nacional no gozaría de la misma amplitud.

La aplicación de la doctrina de margen de apreciación en el contexto del sistema interamericano de protección de los derechos humanos puede encontrar, aparte de la oposición de muchos autores, varios otros obstáculos. En primer término se debe considerar que existe una clara diferencia entre el texto de la Convención Americana y el Convenio Europeo de Derechos Humanos en relación con la libertad de expresión. Como se ha explicado en las páginas anteriores, uno de los objetivos perseguidos por la Convención Americana ha sido reducir al máximo el ámbito de discreción de las autoridades nacionales. Así se explica que el Artículo 13 de la Convención Americana contenga una expresa prohibición de la censura y sólo acepte un sistema de responsabilidades ulteriores. Además de este obstáculo, es necesario tener presente también los principios de interpretación de la Convención que se contienen en su Artículo 29 y que restringen las posibilidades de flexibilizar los preceptos de la misma.

\section{En el contexto europeo, el margen de apreciación se justificaría por la imposibilidad de identificar una concepción común sobre ciertos valores morales.}

Sin ánimo de entrar a examinar en detalle los posibles caminos a seguir para salvar estos obstáculos, está claro que la vía más directa es proponer una reforma del sistema interamericano de derechos

${ }^{59}$ Corte Europea de Derechos Humanos, caso Sunday Times, pärrafo 59.

${ }^{60}$ En esta parte se sigue el estudio realizado por Prebensen. "The Margin of Appreciation and Articles 9, 10 and 11 of the Convention", en Human Rights Law Joumal, (1998, Vol. 19, No 1), pág. 14 y ss. En relación con los criterios aplicables a la generalidad de los derechos, ver Mahoney, loc.cit (supra n.55). 
humanos, a fin de poder enfrentar los nuevos desafíos que plantea la relación entre democracia y derechos humanos, en que estos últimos pueden interferir con el establecimiento de una verdadera democracia abierta y plural. Este problema es claro en materia de libertad de expresión cuando la propia libertad de expresión que ejercen algunos deja a muchos otros sin posibilidad de expresarse. La solución a esta 'ironía de la libertad de expresión' 61 requiere de una visión más amplia sobre los derechos humanos que no se conforma con la posición liberal clásica.

\section{En la medida en que se afirme que los derechos no se transan, la democracia se relega al ámbito de los intereses menos importantes.}

Los derechos, en la medida que se acepta su carácter contramayoritario y apolítico, paradójicamente se convierten también en una amenaza para la posibilidad de establecer un robusto proceso democrático porque, en la medida que se afirma que los derechos no se transan, la democracia es relegada al ámbito de los intereses menos importantes. De esta manera, quien logre transformar su interés en un derecho humano logra imponerse sobre las opiniones e intereses de cualquier otro. Si ese derecho humano consiste en hablar, su carácter fundamental limitará las posibilidades del gobierno de limitar el volumen de las expresiones, de tal manera que quien sea capaz de hablar más fuerte acallará a los demás. La opción ante esta postura propone dejar de concebir los derechos como el límite de la política y aceptar que el desacuerdo sobre los mismos es legítimo y que el mejor lugar para llegar a soluciones de compromiso entre los diversos miembros de la sociedad es el espacio público. La solución podrá implicar la restricción de ciertos derechos en función del mantenimiento de una sociedad verdaderamente democrática. Ése es el desafío para las sociedades latinoamericanas: confiar en que el debate abierto y pluralista realmente puede ser la mejor forma de proteger los derechos humanos.

\footnotetext{
${ }^{61}$ La expresión ha sido tomada del título del libro por Owen Fiss.
} 